\title{
APLICAÇÃO DO JOGO DE DOMINÓ NA EDUCAÇÃO FUNDAMENTAL I: ELUCIDANDO OS NUMEROS NO COTIDIANO DO ALUNO \\ Maria Inês Araújo ${ }^{1}$ \\ Solange Mello Ribeiro ${ }^{2}$ \\ Beatriz Maria de Souza ${ }^{3}$ \\ luri Rojahn da Silva ${ }^{4}$
}

Resumo: A matemática acompanha a evolução da humanidade, projetando as necessidades para um futuro melhor, as formas de ensino muitas vezes não transmitem essa realidade. Para aproximar o aluno ao conhecimento matemático este projeto apresenta de forma lúdica as diversas utilidades dos números fazendo uso do jogo de dominó em peças de Ethil Vinil Acetat (EVA). Possibilitou o desenvolvimento de atividades associadas ao cotidiano dos alunos, onde os temas abordados expressam a fixação do conceito de par ou impar, contribuindo para abstração do significado único e pessoal do conceito numérico. Proporcionando meios para convivência harmoniosa entre docente e discente, na observância das regras constroem-se noções de ética e cidadania trabalhando a linguagem oral transcrita para a linguagem matemática. O trabalho envolveu as operações de adição e subtração, possibilitando a construção de conhecimento matemático.

Palavras-chave: Matemática; Ludicidade; Números; Jogos; Ensino Fundamental.

\footnotetext{
1 Pedagogia/Univap - Universidade do Vale do Paraíba/FEA- Faculdade de Educação e Artes, Brasil E-mail: maria.inesaraujo@yahoo.com.br.

2 Pedagogia/Univap - Universidade do Vale do Paraíba/FEA- Faculdade de Educação e Artes, Brasil E-mail: solangezouzamello@gmail.com.

3 Pedagogia/Univap - Universidade do Vale do Paraíba/FEA- Faculdade de Educação e Artes, Brasil E-mail: beatrizmaria534@gmail.com.

4 Pedagogia/Univap - Universidade do Vale do Paraíba/FEA- Faculdade de Educação e Artes, Brasil E-mail: iuri@univap.br.
} 